\title{
Economic Geography, Comparative Advantage and Trade within Industries: E vidence from the OECD
}

\author{
David Greenaway \\ Centre for Research in Globalisation and Labour M arkets University of N ottingham \\ Johan Torstensson \\ Lund University, FIEF, Stockholm and CEPR
}

\begin{abstract}
A large share of world trade, especially among the OE CD countries, is twoway trade within industries, so called intra-industry trade. Despite this, few attempts have been made to examine why countries export some products with in industries, whereas they import others. We examine this issue, by focusing on the shares of IIT that are vertical and horizontal and by examining price dis persion. The regression results suggest that an abundant human capital endowment as well as a large domestic market increases the quality of OECD-

\footnotetext{
* Correspondence Address: School of E conomics, University of N othingham, University Park, N othingham, NG7, 2RD, England, (Tel) 115-951-5469, (Fax) 115-951-5552, (Email) David.Greenaway@Nothingham.ac.uk.

The first draft of this paper was presented at a CEPR conference in Paris in M ay 1997 and at the Royal Economic Society Annual Conference at Warwick U niversity in April 1998. Feedback from participants at both conferences has helped improve the paper, as have detailed comments from Rod Falvey and Chris M ilner. Greenaway gratefully acknowledges financial support from the Leverhulme Trust under Programme Count F114/ BF.
}

(C2000 - Center for International Economics, Sejong Institution. All rights reserved. 
countries' manufacturing exports, thus offering support for comparative advantage models as well as newer geography models. (JEL Classifications: F12, F13) ४Key Words: >

\section{Introduction}

It is difficult to overstate the importance of analysing the underlying causes of industrial specialisation and international trade. Without a knowledge of their causes, one cannot predict their effects, nor are analyses of trade and industrial policies especially fruitful. A large number of studies have examined determinants of net trade and industrial specialisation. ${ }^{1}$ However, these have dealt exclusively with trade between industries, ignoring determinants of trade within industries, despite the fact that a large share of world trade consists of so called intra-industry trade (IIT). ${ }^{2}$ The first part of this study, therefore, examines, for the OECD-countries, determinants of trade within industries. ${ }^{3}$

The second part examines changes in industrial location within industries as trade costs are reduced. Is production of particular varieties becoming more or less concentrated? Studying changes in location at the industry level may seriously underestimate total structural changes, if there are also

1. Most empirical studies have taken as their starting point in the Heckscher-Ohlin model where net trade is determined by factor proportions. The empirical evidence is somewhat mixed. However, during the last few years, some studies have offered stronger empirical support for the H-O model, especially if complemented by the other main explanation of comparative advantage: technological differences. See Trefler, 1995, Davis and Weinstein [1996], Davis et al [1996], Harrigan [1996]. For a recent review of the evidence see Learner \& Levinsohn [1995].

2. On reasonable levels of aggregation, it is possible that at least half of world trade consists of IIT (see Greenaway and M ilner [1986]), and this share is even higher in trade between OECD-countries.

3. This part of the study is therefore methodologically more similar to earlier studies of inter-industry specialisation and trade than to earlier studies of IIT, since they have typically asked why the share of IIT is particularly high in some industries, for some countries or in some bilateral trade flows.

4. Only one study has examined this issue: that of the European Commission which examines trade specialisation between 1980-1994. Although they find some evidence that at the industry level, there is a slight convergence of manufacturing structures, 
important intra-industry changes. It is, for example, possible that the adjustment consequences of horizontal intra-industry trade (HIIT) differ from those of vertical intra-industry trade (VIIT) with the social costs of the latter being higher and more in line with those of inter-industry change. ${ }^{4}$

The remainder of the paper is organised as follows. Section II sets the scene by reviewing some general considerations relating to specialisation, trade and structural change. In Section III we set out alternative theoretical models of trade within industries which informs the empirical framework of Section IV. The results of estimating our empirical model are discussed in Section V. Finally, Section VI concludes.

\section{Specialisation, Trade and Structural Chance within Industries: Some General Considerations}

Theoretically, the most widely used framework for explaining IIT is monopolistically competitive models where trade is driven by scale economies and horizontal product differentiation. In the simplest case, with no trade costs, trade within industries is indeterminate so country specialisation cannot be predicted. But, this version does not perform well empirically. ${ }^{5}$

We therefore want to deal with the determinants of IIT in the same manner as we would analyse net trade specialisation. Is that possible? $N$ ot if the assumptions of the monopolistic competition model were exactly true empirically. Then, all products would have identical factor-intensities, scale

their results also suggest that within industries, there is some tendency towards increased concentration along the lines of vertical IIT and of increased price dispersion.

5. A first generation of empirical tests of IIT seemed to offer some confirmations of the monopolistic competition and horizontal differentiation explanation of IIT (see Greenaway and M ilner [1987], for a survey of industry and country studies and Helpman [1987], for an influential study of the country pattern of IIT). In recent years, however, quite damaging evidence to the monopolistic competition explanation of horizontal IIT has been offered. In particular, the results in Torstensson [1996] suggest that industry determinants of IIT are very sensitive to various econometric problems. M oreover, the results in Hummels and Levinsohn [1995] cast some doubt on the usefulness of monopolistic competition as explaining the country pattern of IIT. 
economies would be equally important in the production of all products and which country specialised in the production of which specific differentiated products would be completely arbitrary. On the other hand, if products within an industry differ in some more fundamental respect, an analysis of determinants of trade within industries is feasible. Differences may originate in demand or supply. We concentrate on supply and assume that products within an industry differ either in factor-intensities ${ }^{6}$ or in the degree to which scale economies are important. ${ }^{7}$

Following Falvey [1981] and Falvey and Kierzkowski [ 1987] we assume that equilibrium capital-intensities are increasing in quality of vertically differentiated products. We also assume that scale economies increase with quality for which there are two justifications: first, fixed costs for product development seem to be more important for high- than for low-quality varieties and, second, different high-quality varieties are likely to be less close substitutes for each other than are different low quality varieties. With monopolistic competition, the ratio of average to marginal costs depends, in equilibrium, only on the elasticity of substitution between different varieties of a good. So, with a low elasticity of substitution as with high-quality varieties, in equilibrium scale economies will be important.

Casual empiricism supports this assumption and the results in Greenaway, Hine and M ilner [1995] offer some indirect support. They examine, separately, determinants of vertical and horizontal IIT and show that they do differ. In particular, while vertical IIT seems to be associated with markets that are characterised by a large number of firms, horizontal IIT seems to be associated with a low degree of scale economies and a small number of firms.

6. This is, however, certainly not to argue that IIT is a statistical artefact. By adding together products with different factor-intensities or technologies, without other reasons to constitute an 'industry', in the same statistical product group, IIT could be explained in a simple $\mathrm{H}-\mathrm{O}$ fashion. However, the persistence of IIT at very low levels of aggregation suggest that it is a real phenomenon.

7. We are generally not able to examine differences in technologies within industries, although this case may be important empirically. See Davis [1995] for a theoretical model where such differences give rise to IIT. 


\section{Theoretical Models of Trade within Industries}

We can think of general considerations more formally. First, we consider a simple $\mathrm{H}-\mathrm{O}$ framework then a simple economic geography model. Our aim is to test whether the same type of empirical explanations of trade within industries as those proposed earlier as explanations of trade between industries hold.

\section{A. Heckscher-Ohlin and Trade within Industries}

In its simplest version the $\mathrm{H}-\mathrm{O}$ model predicts that the relatively capitalabundant country will export the capital-intensive good whereas the labourabundant country exports the labour-intensive good. Various generalisations to higher dimensions have been made. In general the theory holds, at least as cor relations so that countries will on average export those products that make an intensive use of their relatively abundant factors (see e.g. Deardorff [1982]). So what use of this can he made in studying trade within industries? The answer lies in reinterpreting the general term "product". In brief two products may either belong to the same industry or to two different industries. Consider therefore one of the simplest generalisations of the $\mathrm{H}-\mathrm{O}$ model: the two factor, many country and many product version by Jones [1974] and Deardorff [1979]. Initially, let us assume constant returns and a market structure of per fect competition.

This can be illustrated via the Lerner-diagram set out as figure 1. For simplicity, we consider only one industry ${ }^{8}$ and five qualities. The unit-value isoquants for the products show combinations of capital and labour that can produce one unit of output. There are three countries. The unit-isocost lines $\mathrm{w}_{\mathrm{j}}$ define combinations of capital and labour that cost one unit in country $\mathrm{j}$. Because price in equilibrium equals average cost, the unit-value isoquant must be tangential to the isocost lines when a product is actually produced by countr $y \mathrm{j}$. The rays from the origin, $\mathrm{k}_{\mathrm{j}}$, illustrate the capital-labour ratios of the three countries. The figure shows that the most capital abundant

8. The inclusion of more than one industry would not change the implications with regard to the direction of intra-industry trade. 
country A produces the two products with highest qualities, 1 and 2. Country $B$ has an intermediate capital-labour ratio and produces products 2,3 and 4 . The most labour-abundant country $C$ produces the two products with the lowest quality, 4 and 5 . This suggests a positive relationship between the capital-labour ratio of countries and the quality of vertically differentiated products in their exports.

\section{B. E conomic Geography and Trade Within Industries}

An alternative is to suppose that trade within industries is determined by scale economies and market access. Consider a reinterpretation of the $\mathrm{Help}$ man-K rugman ([1985], chapter 10) model. Assume that all factors are industry-specific but there is only one factor specific to each industry, labour. There are two countries, $A$ and $B$, that have access to identical technologies and two qualities within each industry. The low quality variety is produced under constant returns to scale and perfect competition. This captures the assumptions that fixed costs for product development are relatively unimportant in low-quality varieties and that different low-quality varieties are close substitutes for each other. On the other hand, high-quality varieties are produced under increasing returns to scale and monopolistic competition which captures the assumption that product development is important in the production of high-quality varieties and that different high-quality varieties are imperfect substitutes.

For simplicity, assume that there are constant expenditure shares on high- and low-quality varieties, i.e. there is a low elasticity of substitution between the two. In turn, this means that we can in effect treat the markets for low- and high-quality varieties as separate and assume perfect competition in the low-quality market and monopolistic competition in the high-quality market. Although some models predict 'small numbers' when vertical product differentiation is present (e.g. Gabszewicz, Shaked, Sutton and Thisse [1981]), others have a 'large numbers' outcome (e.g. Falvey [1981]).

In formal terms the sub-utility function for industr $\mathrm{X}$ is: 


$$
U_{x}=\left(\sum_{i=1}^{n} h_{j}\right)^{y} L^{1-y}, 0<<1,=1-(1 / \quad)
$$

where $h_{j}$ is the consumption of high-quality varieties in industry $X$ and $L$ consumption of the (only) low-quality variety. Without loss of generality, we can choose units so that GDP is one in country $A$ and $L$ units in country $B$. Finally, we assume zero trade costs prevail in production of low-quality varieties but that there are trade costs in high-quality varieties. This means that only a certain part $(1 / \tau, \tau>1)$ of each exported unit is received by the importer. Finally, we assume that all countries in all industries have some production of low-quality varieties. ${ }^{9}$ This means that wage rates throughout are equalised across countries.

\section{The Analysis}

Given our assumptions, aggregate demand for high-quality products produced in the two countries will be:

$$
\begin{aligned}
& D_{A}=n_{A} x_{A}=\left[\begin{array}{ll}
n_{A} p_{A}^{-} & ] /\left[n_{A} p_{A}^{1-}+n_{B}\left(p_{B}\right)^{1-}\right]
\end{array}\right] \\
& +\left[\left[\begin{array}{ll}
n_{A}\left(p_{A}\right)^{-} & L
\end{array}\right] /\left[n_{A}\left(p_{A}\right)^{1-}+n_{B} p_{B}\right]\right] \\
& D_{B}=n_{B} x_{B}=\left[\left[n_{B}\left(p_{B}\right)^{-}\right] /\left[n_{A} p_{A}^{1-}+n_{B}\left(p_{B}\right)^{1-}\right]\right] \\
& +\left[\left[\begin{array}{ll}
n_{B} p_{B}^{-} & L
\end{array}\right] /\left[n_{A}\left(p_{A}\right)^{1-}+n_{B} p_{B}\right]\right]
\end{aligned}
$$

where $D_{A}$ and $D_{B}$, are the demand for high-quality products produced in country $A$ and $B$, respectively; $n_{A}$ and $n_{B}$ are the number of high-quality firms in country $A$ and $B$, respectively; and $x_{A}$ and $x_{B}$ are output per highquality firm in the two countries; $\gamma$ is the share of expenditure devoted to high-quality varieties. The first term in each expression therefore represents demand from country $A$ and the second term demand from country B. Production is undertaken with increasing returns to scale. Each firm's average cost in production of high-quality varieties in country $j$ is:

9. Davis [1997] shows that this assumption can be critical for the theoretical results we obtain. However, whether the model still works well or not is ultimately an empirical question. 


$$
A C_{x j}=w+\left(w / x_{j}\right)
$$

where $\eta w$ is the constant marginal cost, $\mu \mathrm{w}$ fixed cost and $x_{j}$, output per firm. From the assumptions that profits are driven to zero, and firms maximise profits by setting marginal revenue equal to marginal cost, we derive equilibrium output per firms as:

$$
x=(/((1-))
$$

Thus, output per firm will necessarily be equalised across countries. In this context, it can be shown that the equilibrium number of firms in each country equals:

$$
\begin{aligned}
& n_{A}=[(1-L)] /[(1-) x] \\
& n_{A}=[(L-)] /[(1-) x]
\end{aligned}
$$

where we define ${ }^{1-}=<$.

By inspection of (3a)-(3b), we can see that the larger country will always be a net exporter of high-quality varieties, whereas the small country will export the low quality variety. This is driven by the constant expenditure shares of the two qualities; net trade is determined by whether the ratio of $n_{A} /\left(n_{B} L\right)$ is greater or smaller than one. From (3a) and (3b), this ratio is given as: $(1-\rho L) /(L(1-\rho))$. Clearly, the question of whether it is greater or smaller than unity reduces to whether $\left(1-L^{2}\right) \gtrless 0$ Thus, if for example country $A$ is the larger country $(L<1)$, it is also a net exporter of high-quality products and imports low-quality products.

It is also easy to show that the net export of high-quality varieties will be higher, the more important are scale economies and the larger the difference in country size. Furthermore, reductions in trade costs will increase net specialisation such that production of high-quality varieties will gradually become more concentrated in the large country. Trade within these industries will therefore increasingly take place in different qualities. In other words, IIT in vertically differentiated products will tend to increase whereas that in horizontally differentiated products decreases.

\section{An Empirical Framework}


Thus, we have two theoretical frameworks, one in which relative factor abundance and another in which relative country size, determines trade within industries. We now test whether market access and relative capital endowment affects the quality of products by regressing quality in trade on measures of market access, such as the size of the home market. Then we examine whether production within industries is becoming more specialised. In addition to regression analysis, we calculate the share of total trade that is HIIT and VIIT, respectively. Finally, we calculate whether import price dispersion has increased. In doing this, we examine quality in all manufacturing products (ISIC 3 ). Since the data requirements are extremely demanding, we restrict ourselves to examining imports into Sweden, on the assumption that OECD-countries' exports to Sweden broadly reflect the quality of total $O E C D$ exports. There are no a priori reasons to expect that exports to Sweden are not representative of OECD countries' total exports.

We work at the 6-digit level of SNI, the Swedish ISIC-based classification where there are 169 industries. At this level of aggregation, it is plausible to assume that price differences do in fact pick up quality differences reasonably well, even in the case where consumers have imperfect information (see Stiglitz [1987]). ${ }^{10}$ In line with other multi-industry studies of trade we start from the position that at such disaggregated levels relative prices do in most ways reflect relative qualities (see Torstensson [1991], Abd-el-Rahman [1991], Greenaway, Hine \& M ilner [1994, 1995], European Commission [1996]).

Let us now focus on the first hypothesis. M ore specifically, assume that quality in imports from country $j$ in industr $y \mathrm{~h}$ can be expressed as:

$$
Z_{h j}={ }_{1 h} \operatorname{HCAP}_{j}{ }^{2}, \text { PCAP }_{j}{ }^{3}, \text { MARKSIZE }_{j}{ }^{4}
$$

10. With vertical differentiation, we assume that all individuals had the same ranking of products. The only reason for an individual to consume a low-quality rather than a high-quality product is that the low-quality product has a lower-price. Thus, if two products are offered at the same price, all individuals will choose the product with the higher quality (Sutton [1986]). Assuming that consumers have perfect information one can conclude that if one product in an industry is sold at a higher price than another, the former must have a higher quality. Consequently, ranking of products according to price should correspond to a ranking according to quality. 
where, HCAP is human capital endowment, PCAP is physical capital endowment, MARKSIZE is domestic market size. So, consider the following regression:

$$
\ln z_{h j}=1 n{ }_{1 h}+{ }_{2} 1 n H C A P_{j}+{ }_{3} 1 n P C A P_{j}+{ }_{4} 1 n M A R K S I Z E_{j}
$$

Positive coefficients for the variables for capital endowments (PCAP, HCAP) are consistent with support for Heckscher-Ohlin; a positive coefficient for M ARKSIZE suggests support for geography models. If none of the coefficients were significant, this offers indirect support for the simplest monopolistic competition model.

As in Leamer [1984] and others, we measure the endowment of physical capital, PCAP, by the depreciated sum of cumulated gross domestic investment, as capital stock per worker in PPP terms from the Summers and Heston [1991] database. This is a fairly straightforward and probably reasonably accurate measure of the relative endowment of physical capital. It is more difficult to construct useful measures of human capital endowment. However, Barro and Lee [1996] provide data on school attainment for persons over 15 and 25 respectively, for five-year. intervals from 1960-1990. We use three measures front Barro and Lee and, since in the OECD, only a small proportion of the labour force starts working at the age of 15 , we concentrate on school attainment for persons over 25. The first measure is the mean school years (HUMCAP1), the second and third are the shares population that have completed secondary and higher education, respectively. These are denoted HUMCAP2 and HUM CAP3). M arket size (MARKSIZE) is somewhat more straightforward, with total GNP expressed in PPP.

The equations were estimated for 1969, 1981 and 1994, ${ }^{11}$ first for each of the years separately, then pooled to construct a panel where we allow both the intercept and slope coefficients to vary across time. Clearly, since price levels change, we expect the intercepts to differ across time periods. The slope coefficients will differ if determinants of trade within industries change over time. The role of capital endowments could change over time, but there are a priori reasons to expect this. However, theory does provide

11. Note that since the intercept is industry-specific, one dummy for each industry is included in the empirical model and the dummies are treated as fixed effects. 
us with explicit a priori reasons to expect the coefficients capturing market access to change through time since reductions in trade costs could have an effect on the location of high-quality production. $N$ ote, also that we do not attempt to explicitly link factor-intensities and scale economies to quality. In this sense, our approach is similar to that used in inter-industry production and trade studies (e.g. Leamer [1984], Davis and Weinstein [1996] and Harrigan [1996]).

In addition to regression analysis, we also ask whether horizontal or vertical IIT has increased most. We distinguish between the two following Greenaway, Hine and M ilner [1994, 1995]. They start from the assumptions that quality is reflected in price which can be proxied by unit values. Specifically, suppose:

$$
I I T_{j}=1-\frac{\Sigma\left|X_{i j}^{p}-M_{i j}^{p}\right|}{\Sigma\left|X_{i j}^{p}-M_{i j}^{p}\right|}
$$

where $p$ refers to horizontally or vertically differentiated products and $\mathrm{i}$ refers to fifth digit SITC products in a given third digit industry. Then

$$
B_{j}=H B_{j}+V B_{j}
$$

where $H B_{j}$ is given by (5) for those products (i) in $j$ where unit values of imports $\left(U V_{i j}^{m}\right)$ and exports $\left(U V_{i j}^{x}\right)$ for a given dispersion factor, satisfy the condition:

$$
1-a \leq \frac{U V_{i j}^{x}}{U V_{i j}^{m}} \leq 1+
$$

and $V_{B_{j}}$ is given by (5) for those products (i) in $\mathrm{j}$ where:

$$
\frac{U V_{i j}^{x}}{U V_{i j}^{m}}<1-\quad \text { or } \frac{U V_{i j}^{x}}{U V_{i j}^{m}}<1+
$$

Greenaway, Hine and M ilner [1994, [1995] calculate HIIT and VIIT for the UK using both $\alpha=0.15$ and $\alpha=0.25$. Even with the latter, VIIT remains very significant, indeed as important as HIIT. Using the narrower wedge of 15\% VIIT turns out to be clearly the most important form of IIT in UK trade. In this study, we use both $15 \%$ and $25 \%$ When the narrower wedge is used, we define the variables HIIT1 and VIIT1 and with a 25\%wedge, HIIT2 and VIIT2.

Another method of examining vertical and horizontal IIT is through mea- 
suring changes in the coefficient of variation of import prices within each and every industry. If countries increasingly specialised in varieties with similar qualities, the coefficient of variation could be expected to decrease. But, if they specialised in varieties of different qualities, this would be reflected in greater price dispersion and therefore an increased coefficient of variation.

\section{Results}

\section{A. Determinants of Trade Within Industries}

Regression Results The regression results are presented in Tables la and $\mathrm{lb}$. The first presents results from the individual regressions, the second from the panel regressions. B efore commenting on the Tables, two remarks are in order. First, although we estimated equation $4 \mathrm{~b}$ using three alternative measures for human capital, the results are presented only where HUM CAP is used, since the choice of which human capital variable to include affects neither the other variables nor the estimated effects of human capital on quality. Second, since we work with cross-section data, we make corrections for heteroscedasticity using the method introduced by White [1980].

Table 1a

Regression Results; Individual Years

\begin{tabular}{|c|c|c|c|}
\hline Variable & 1969 & 1981 & 1994 \\
\hline \multirow{2}{*}{ HCAP } & 0.108 & 0.257 & 0.274 \\
& $(3.72)$ & $(9.99)$ & $(6.91)$ \\
\hline \multirow{2}{*}{ PCAP } & -0.0005 & -0.156 & 0.072 \\
& $(-0.01)$ & $(-3.85)$ & $(1.54)$ \\
\hline \multirow{2}{*}{ M ARKSIZE } & 0.097 & 0.095 & 0.111 \\
& $(8.58)$ & $(8.49)$ & $(8.65)$ \\
\hline N & 2313 & 2572 & 2597 \\
\hline
\end{tabular}

heteroscedasticity-consistent t-statistics within parentheses. 
Table 1b

Regression Results; Panel data

\begin{tabular}{|c|c|rr|}
\hline Variable & $\begin{array}{c}\text { Restricted } \\
\text { Coefficients }\end{array}$ & \multicolumn{2}{|c|}{$\begin{array}{c}\text { Country/Time } \\
\text { dummies }\end{array}$} \\
\hline HCAP69 & $0.204(12.28)$ & $0.110(3.64)$ \\
\hline PCAP69 & $-0.036(-1.50)$ & $-0.019 \quad(-0.48)$ \\
\hline M ARKSIZE69 & $0.093(13.14)$ & $0.093 \quad(7.84)$ \\
\hline HCAP81 & & $0.145 \quad(3.80)$ \\
\hline HCAP94 & & $0.164 \quad(3.34)$ \\
\hline PCAP81 & & $-0.137 \quad(-2.46)$ \\
\hline PCAP94 & & $0.089 \quad(1.41)$ \\
\hline M ARKSIZ81 & & $0.001 \quad(0.06)$ \\
\hline MARKSIZ94 & & $0.018(0.99)$ \\
\hline$n$ & 7482 & \multicolumn{2}{|c|}{7482} \\
\hline
\end{tabular}

heteroscedasticity-consistent t-statistics within parentheses.

As the Tables show, both human capital endowment and total size of the home market, affect the quality of exported products positively. The importance of human capital for trade within industries seems to increase over time. The coefficient for total market size is positive throughout with high tstatistics. But, relative endowments of physical capital do not seem to affect the results in a consistent manner. The coefficient for physical capital is sometimes positive sometimes negative. In 1981, it is even negative and significant. However, in the other years, it is mostly positive and in combination with some of the variables for human capital, sometimes positive and significant.

Table Ib presents the panel results. In the second column, we restrict the coefficients of interest to be equal in all three periods (and thus only allow for a general price change between periods). Still, the coefficients for human capital and market size are positive and significant, with high t values. In the third column of Table $1 b$, we allow the country coefficients to change over time, by interacting the variables with time-dummies. It is clear that the coefficient of human capital increases from 1969 to 1981 and 1994, since the HCAP81 and HCAP94 are both statistically significant. The market 
size variable is, however, more or less unchanged from 1969 onwards.

It is also noteworthy that the relationship between human capital endowment and the quality of exports is robust. Although our three measures are quite similar, two problems remain. ${ }^{12}$ First, it is only able to capture the quantity and not quality of education and, secondly, it does not distinguish between different types of education. Data that is cleansed of such factors are difficult to obtain. However, in OECD E ducation at a Glance, data on science and engineering personnel between the ages of 25-34 as a proportion of the labour force are available for 16 OECD-countries and we experiment with this as HUMCAP4. Finally, the variable HUMCAP5 attempts to take quality of education into account. The Third International Maths and Sci ence Study sets out to evaluate this in $M$ aths and Science in 41 countries, out of which 18 are OECD-countries. The results of using HUMCAP 4 and HUM CAP 5 are interesting. Although the correlation between the two is low as is the correlation between these and the three other measures of human capital, in 1981 and 1994 they also positively and significantly affect the quality of exports. So, different aspects of training and human capital seem to be important in determining trade within industries.

\section{B. Exploring Robustness}

Thus human capital and market size do seem to have an effect on the pattern of trade within industries. However, a number of potential limitations should be acknowledged. First the restrictive structure imposed on the model amounts to assuming that the effects of capital endowment and country size should be similar across industries. ${ }^{13}$ This was subsequently tested by using industry dummies interacting with the country characteristics.

12. They all are quite highly correlated with each other, with the simple correlation coefficients being around 0.7 .

13. An alternative approach may therefore be to use a disaggregation of industries and estimate determinants of each industry separately. Such an approach has been used by Hansson [1993] with somewhat mixed results. Relative factor endowments are good predictors of the trade patterns in some of the industries while in the majority they are not. In particular textiles and clothing are factor endowments good predictors. 
The assumption of the interaction coefficients being equal to zero could, at the $5 \%$ level, not be rejected for either year or characteristic. We take this as reassuring.

Second, although the coefficients are mostly highly significant it should be noted we have a very large number of observations. The conventional classical t-values may not therefore be appropriate. Leamer [1978] presents the asymptotic Schwartz-Leamer t-value which is equal to $\left[\left(T^{1 / T}-1\right)(T-1)\right]^{0.5}$ where $T$ is the degrees of freedom. Even if we use this stronger criterion, all the coefficients for human capital and market size remain significant.

Third, since the variables capturing capital endowment and market size are proxies, we want to ensure that measurement errors do not affect the results. Therefore, we use the reverse regressions test by K lepper and Leamer [1984]. The results (available on request), show that the variables for human capital and market size are both bounded and therefore inferences can be drawn even assuming measurement errors.

F ourth, there may be non-normality of the error terms. We therefore perform a joint test for skewness and kurtosis as suggested by Shapiro-Wilk [1965]. The hypothesis of normality at the $5 \%$ level can be rejected for all regressions. In this case, robust regressions should be preferred. ${ }^{14}$ The results are presented in Table 2 . The main conclusions from the OLS estimation are upheld and even somewhat strengthened.

Fifth, it may be that country-specific and time-independent factors do affect the results in addition to the country characteristics. Therefore, we used the panel to introduce country-specific fixed effects (but also experiment with random effects without this affecting the results). The results (again available on request) show that both the human capital and market size variables are still positive and significant.

Finally, unit import prices are recorded c.i.f, i.e. inclusive of costs of transportation. If such costs are substantial and differ across exporters, this may affect the results. Country dummies may pick up transportation costs. These should be lower for European than for non-European exporters.

14. We have used the "robust regression "employed by STATA. It works iteratively first by performing a regression, calculating weight based on residuals and then using these weights for further regressions until changes in weights drop to a certain level. 
Table 2

Vertical (VIT) and Horizontal (HIIT) Intra-Industry Trade as Percentage of Total Trade

\begin{tabular}{|c|c|c|c|c|}
\hline Year & HIIT1 & HIIT2 & VIIT1 & VIIT2 \\
\hline 1969 & 0.077 & 0.125 & 0.319 & 0.270 \\
\hline 1981 & 0.117 & 0.224 & 0.356 & 0.249 \\
\hline 1994 & 0.126 & 0.208 & 0.389 & 0.305 \\
\hline
\end{tabular}

Table 3

Robust Regressions

\begin{tabular}{|c|c|c|c|c|}
\hline Variable & 1969 & 1981 & 1994 & Pooled \\
\hline \multirow{2}{*}{ HCAP } & 0.120 & 0.278 & 0.269 & 0.222 \\
& $(4.95)$ & $(11.54)$ & $(10.42)$ & $(14.52)$ \\
\hline \multirow{2}{*}{ PCAP } & 0.0001 & -0.122 & 0.086 & -0.022 \\
& $(0.96)$ & $(-2.46)$ & $(2.32)$ & $(-1.22)$ \\
\hline \multirow{2}{*}{ M ARKSIZE } & 0.110 & 0.108 & 0.109 & 0.098 \\
& $(10.22)$ & $(10.52)$ & $(11.20)$ & $(14.43)$ \\
\hline $\mathrm{n}$ & 2313 & 2572 & 2597 & 7482 \\
\hline
\end{tabular}

Therefore we added a European dummy that takes the value of 1 if a country is a member of EC or EFTA and 0 otherwise. The dummy should be positive if it captures costs of transportation. The empirical results are presented in the last column of Table 1b. The European dummy is positive and highly significant as expected if transportation costs affected unit prices. However, the human capital and market size coefficients are still positive and highly significant. In fact, even the variable for physical capital is now positive with a significant t-statistic.

\section{Is Production within Industries Becoming More Specialised?}

We also examined the effects of reduction of trade costs on location of production within industries based on the hypothesis that market size in certain intervals of trade cost could lead to more concentrated production within industries and less concentrated in other intervals. M oreover, reduc- 
tions of trade costs could make factor proportions a more important determinant of quality within industries. So, relocation across industries could seriously underestimate total changes in relocation occurring after trade liberalisation. Consider again Table Ib. By pooling the data, we cannot reject at the $5 \%$ level the hypothesis that the coefficients for market size are the same in the three years. However, the coefficient for human capital clearly increases from 1969 to 1981/ 1994. So, concentration of production does not seem to change over time but lower trade costs lead to increased specialization according to factor proportions.

We also distinguished between horizontal and vertical IIT. An increased share of vertical IIT would suggest a greater concentration of production in different qualities within industries. According to both the narrow and broad definitions, HIIT increased substantially as a share of total trade between 1969 and 1981 (its share of total trade increased by 52\%according to HIIT 1 and by $79 \%$ according to HIIT2). Then it stagnated and, according to HIIT2, fell somewhat. As in the U.K. case, vertical IIT is always higher than horizontal IIT even when the relatively broad wedge of $\pm 25 \%$ is used. The share of vertical IIT increased between 1969 and 1994 according to both definitions. ${ }^{15}$ The increase is more pronounced using VIIT1. With this measure, it increased between 1969 and 1981 and again to 1994. When we instead measure VIIT by means of the broader wedge of $\pm 25 \%$ its share decreased somewhat between 1969 and 1981. Clearly, HIIT seems to have increased in importance between 1969 and 1981 but then stagnated. So, we find little evidence of recent increased dispersion of production with in

15. Two objections could however be made. First, the distinction of VIIT as defined by price differences of $\pm 15 \%$ and $+25 \%$ is essentially arbitrary. But when we compare VIIT vs. HIIT over time the exact cut-off points should not matter too much. M oreoever we have initially used two cutoff points and also experimented with others and the results are similar. Second, one could argue that the fact that Swedish VIIT has increased is driven by chances in Swedish qualities rather than by different countries increasingly exporting products of different qualities. To some degree this is true. The quality of Swedish exports relative to its imports have increased somewhat from 1.80 in 1969 to 2.09 in 1981 and 2.14 in 1994 . However, this could also be interpreted as an indication that vertical IIT could not increase too much in Sweden, since already in 1969, Sweden was specialized in the production of high-quality varieties. 
industries. But, whether we can conclude that production is getting more concentrated is more difficult.

We also examined the coefficient of variation in import prices. In a large majority of cases it increased from 1969 to 1981 and from 1981 and 1994, suggesting some evidence of specialisation in different qualities within industries. More specifically, in $74 \%$ of the industries price dispersion increased between 1969 and 1981 and in 72\% between 1981 and 1994. So, although the evidence on VIIT and HIIT is somewhat ambiguous, there is other evidence that concentration of production has occurred.

\section{Conclusions}

A large part of world trade is IIT. Although many studies have asked why the share of bilateral trade is higher in some trade and for some countries and industries than for others, few have attempted to examine the determinants of the product pattern of trade. So this was our first aim. Given data constraints we restricted ourselves to imports to Sweden from OECD countries. The first question we asked was whether economic geography or $\mathrm{H}-\mathrm{O}$ factors were more important in predicting trade within industries. It turned out that the answer was both! A large domestic market, and an abundant endowment of human capital increases the quality of exports. M oreover, the results seem to be very robust.

Our second aim was to ask whether concentration of production within industries has increased, so that different countries increasingly specialise in the production of different qualities. Here, the evidence is less clear-cut. We have computed the coefficient of variation in import prices, but no clear tendency emerges. These is some evidence that vertical IIT increases over time, whereas horizontal IIT has stagnated but this evidence is too weak to offer support for this aspect of geography models.

In sum, the results are very promising. Both economic geography and factor proportions variables seem to be important in determining trade within industries. 


\section{References}

Abd-el-Rahman, K. [1991], "Finns' Competitive and National Comparative Advantages as Joint Determinants of Trade Composition," Weltwir tschaftliches Archiv 127; pp. 83-97.

Baldwin, R.E. and Venables, A.J. [1995] "Regional Economic Integration". In: Grossman, G.M . and Rogoff, K. Handbook of International Econom ics, Elsevier, Amsterdam.

Barro, R.J . and J.W. Lee [1996], "International M easures of Schooling Years and Schooling Quality," American Economic Review 86; pp. 218-223.

B rulhart, M. and J. Torstensson, "Regional Integration, Scale Economies and Industry Location in the European Union," CEPR Discussion Paper, N 0.1435.

Davis, D. [1995], "Intra-Industry Trade: A Heckscher-Ohlin-Ricardo Approach," Journal of International Economics.

Davis, D. and D.E. Weinstein, [1996] "Does Economic Geography M atter for International Specialisation?" N BE R Working Paper, N o. 5706.

Deardorff, A.V., [1979], "Weak Links in the Chain of Comparative Advantage," Journal of International E conomics 9; pp. 197-209.

Deardor ff, A.V. [1982], "The General Validity of the Heckscher-Ohlin Theorem," American E conomic Review 72; pp. 683-694.

Dixit, A.K. and J.E. Stiglitz, [1977] "M onopolistic Competition and Optimum Product Diversity," The American Economic Review 67; pp. 297-308.

Falvey, R [1981] "Commercial Policy and Intra Industry Trade," Journal of International Economics 11; pp. 495-511.

Falvey, R.E. and Kierzkowski, H. [1987], "Product Quality, Intra-Industry Trade and (Im) perfect Competition", in Kierzkowski, H. (ed.), Protec tion and Competition in International Trade: Essays in Honour of W.M . Corden, Basil Blackwell, Oxford and London.

Flam, H. and Helpman, E., [1987], "Vertical Product Differentiation and North-South Trade," American E conomic Review 77; pp. 810-822.

Fujita, M and Thisse, J.F. [1996], "Economics of Agglomeration," Journal of the Japanese and International E conomies 10; pp. 339-378.

Gabszewicz, J.J ., Shaked, A., Sutton, J. and Thisse, J.F . [1981], "International Trade in Differentiated Products," International E conomic Review 22; 
pp. 527-533.

Greenaway, D., Hine, R.C. and C.R. Milner, C.R. [1994], "Country-specific

Factors and the Pattern of Horizontal and Vertical Intra-industry

Trade in the UK," Weltwir tschaftliches Archiv 130; pp. 77-100.

Greenaway, D. Hine, R.C. and C.R. M ilner [1995], "Vertical and Horizontal

Intra Industry Trade: A Cross-Industry Analysis for the United Kingdom," Economic Journal 105; pp. 1505-1519.

Greenaway, D. and M ilner, C.R. [1986], The E conomics of Intra-Industry Trade, Basil Blackwell, Oxford.

Greenaway, D. and M ilner, C.R. [1987] "Intra-Industry Trade: Current Perspectives and Unresolved Issues," Weltwirtschaftliches Archiv 123; pp. 39-57.

Greenaway, D. \& Torstensson, J. [ 1997], "B ack to the Future: Taking Stock on Intra Industr y Trade," Weltwir tschaftliches Archiv 133; pp. 249-269.

Grossman, G. and E. Helpman [1991], Innovation and Growth in the Global

E conomy, M IT Press, Cambridge, M ass.

Hanson, G. [1997], "Increasing Returns, Trade and the Regional Structure of Wages," E conomic Journal 107; pp. 113-133.

Hansson, P. [1993], "Product Quality and Vertical Differentiation as Determinants of Intra-Industry Trade in Swedish M anufacturing," FIEF Working Paper, N o. 122.

Harrigan, J. [1996], "Technology, F actor Supplies, and International Specialization: Estimating the N eoclassical M odel," Federal Reserve Bank of New York, Staff Reports, N o 15.

H elpman, E. and Krugman, P. [1985], M arket Structure and Foreign Trade, MIT Press, Cambridge (M ass.).

Hummels, D. and Levinsohn, J. [1995], Monopolistic Competition and International Trade: Reconsidering the Evidence, Quarterly Journal of E conomics 110; pp. 799-836.

Klepper, S. and Leamer, E.E. [1984], Consistent Sets of Estimates for

Regressions with Errors in All Variables, Econometrica 52; pp. 163183.

Krugman, Paul [1980], "Scale Economies, Product Differentiation, and the

Pattern of Trade," American Economic Review 70; pp. 950-959.

Krugman, Paul [1991a], "Increasing Returns and Economic Geography," 
Journal of Political Economy 99; pp. 483-499.

Krugman, Paul [1991b], Geography and Trade, M IT Press, Cambridge (M ass.).

Krugman, Paul and Venables, Anthony J. [1995], "Globalization and the Inequality of Nations," Quarterly Journal of Economics 110; pp. 857880.

Leamer, E. and Levinsohn, J. [ 1995], International Trade Theory: The Evidence, in Handbook of International Economics III, North-Holland, Amsterdam.

M arkusen, J.R. and Venables, A.J. [1996], "The Theory of Endowment, Intra-Industry and M ultinational Trade," CEPR Discussion Paper, No. 1341, February.

Torstensson, J. [1991] Quality Differentiation and Factor Proportions in International Trade: An Empirical Test of the Swedish Case, Weltwir tschaftliches Archiv 127; pp. 183-94.

Torstensson, J . [1996a], "D eterminants of Intra-industry Trade: A Sensitivity Analysis," Oxford Bulletin of E conomics and Statistics 58; N 0.3.

Torstensson, J. [1996b], "Can Factor Proportions Explain Vertical IntraIndustry Trade?," Applied E conomics Letters 3; pp. 307-310.

Venables, A.J . [1987], "Trade and Trade Policy with Differentiated Products: A Chamberlinian-Ricardian M odel," E conomic Journal 97; pp. 700-717. 